\title{
Atlas in a Day Challenge: A Global, Real-time Collaboration
}

On Saturday, Остовer 5, 2019, more than 50 guerrilla cartographers gathered, in person and online, to collaborate in producing an atlas in a single day on the theme of migration. While researching and designing an entire atlas on a complex theme in the span of 24 hours is indeed a challenge, this volume of maps is a concrete demonstration of the power of global, real-time collaboration.

The mission of Guerrilla Cartography is to promote the cartographic arts widely, and to expand the art, methods, and thematic scope of cartography through community workshops and symposia, public exhibitions, and collaborative projects. We imagined the Atlas in a Day challenge as another such collaborative project, one that could bring a diverse group of ideas and people into the mapping process. After all, we had already figured out how to engage a global community in producing a substantial and beautiful atlas in a few months, so why not see what we could do in one day? We knew there would not be time for comprehensive editing, nor money to finance a fine printing, but our main objective was to build a community around a collaborative mapping project, one that could then say something through cartography about an important theme.

The theme of the Atlas in a Day project-migration, broadly defined-was announced to the Guerrilla Cartography collaborative only the night before the challenge, via a livestream at 9 pm Pacific Time, from Federation Brewing in Oakland, California. The following day, some 35 participants met at Oakstop in downtown Oakland, and began sharing ideas and working on maps. Together, we enjoyed invited speakers, food, and collaboration all day long.

\section{Founder Guerrillo Cariography diensen@guerrillacartography.org}

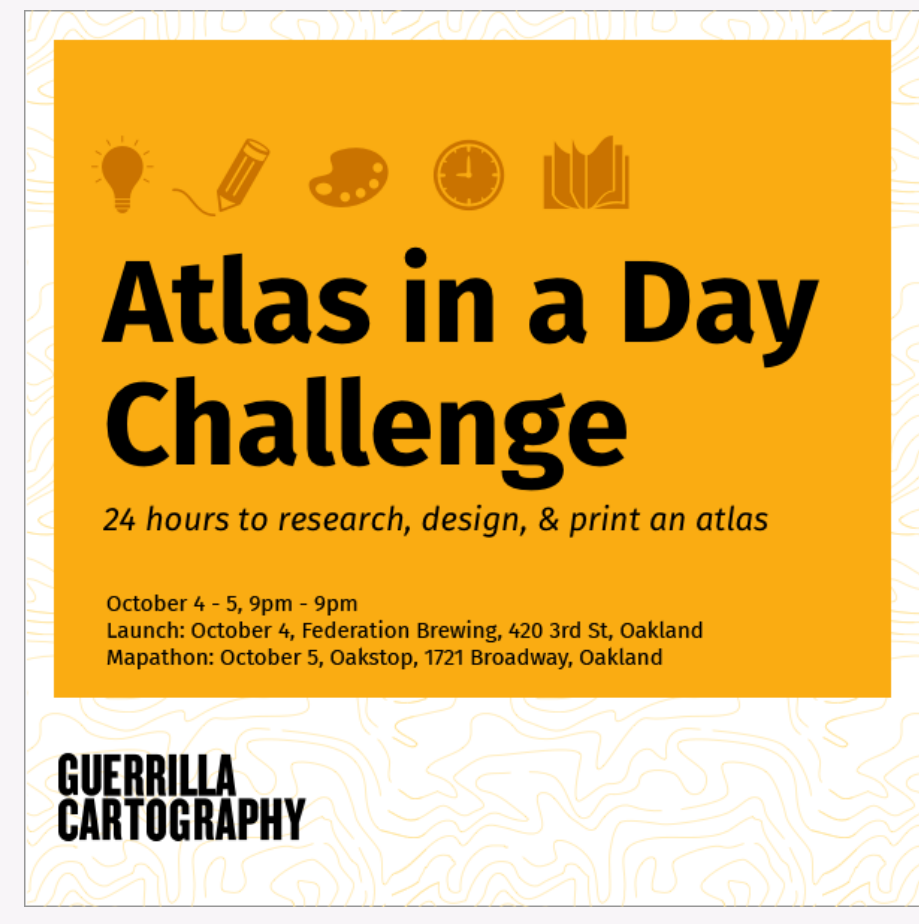

Pre-challenge publicity poster.

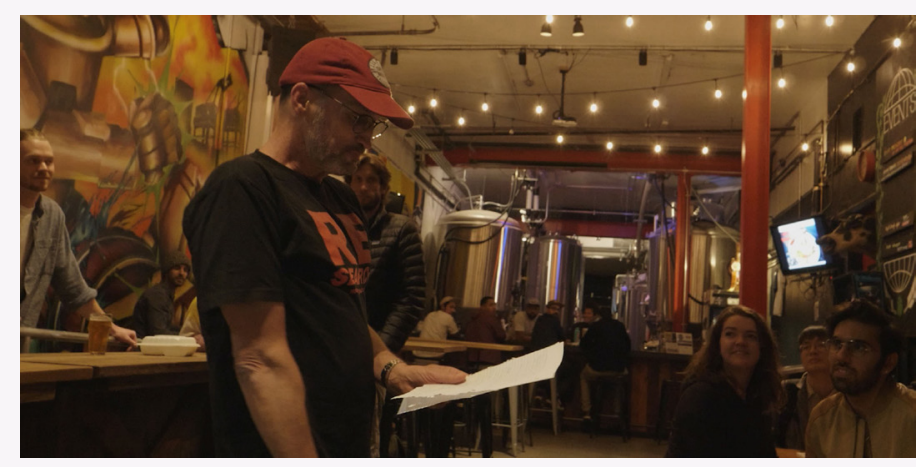

Darin Jensen, announcing the theme live on Facebook.

\section{A DAY OF MAPPING}

With MORNING COFFEE AND DONUTS, we started the day with "Geospatial data from the US Census," as UC
Berkeley economics Ph.D. candidate Zach Bleemer offered a practical demonstration of accessing public census 


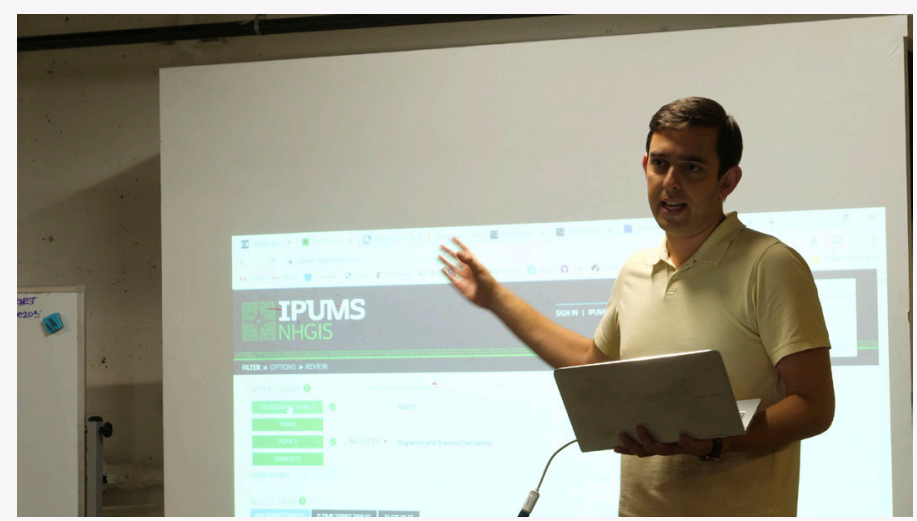

Zach Bleemer.

data. After Zach's demonstration, the guerrillas settled in to working on their maps, mining data, and pulling out art supplies.

At midmorning, our Atlas in a Day keynote speaker, Professor Diana Negrín, an instructor at UC Berkeley and the University of San Francisco, spoke on the ethics of mapping in her talk, "Represent, Visibilize, Dignify." As she described in her abstract,

The practice of mapping is fundamentally anchored to the act of representing places, peoples, species and the less tangible elements that inhabit the spaces where human and non-human life circulate. These acts of representation transmit worldviews that can ultimately lead to material consequences, be they just or unjust. Just as a map can provide perspective and insight into the otherwise unseen, it can also

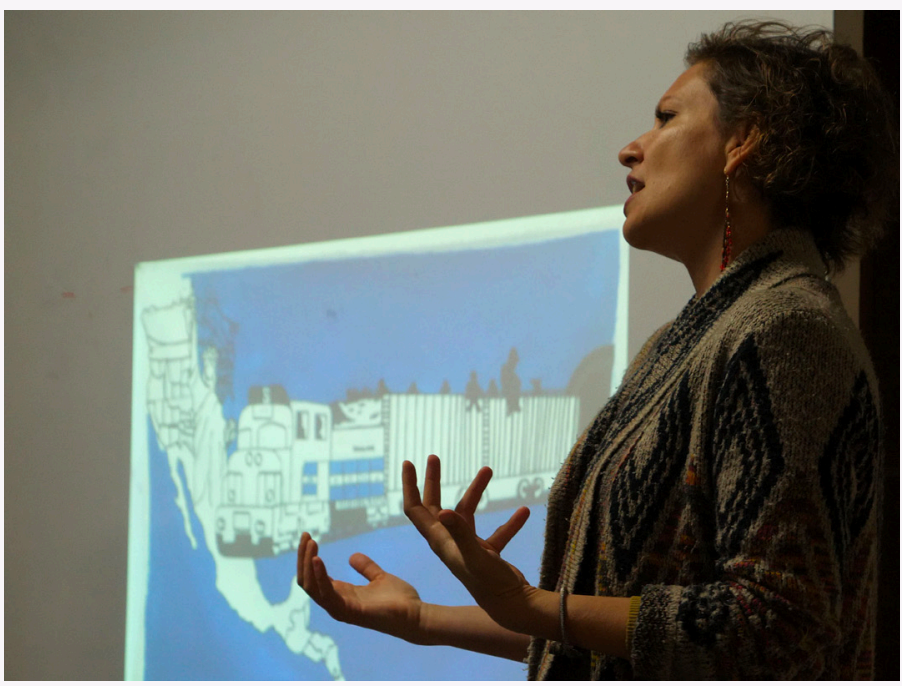

Diana Negrín.

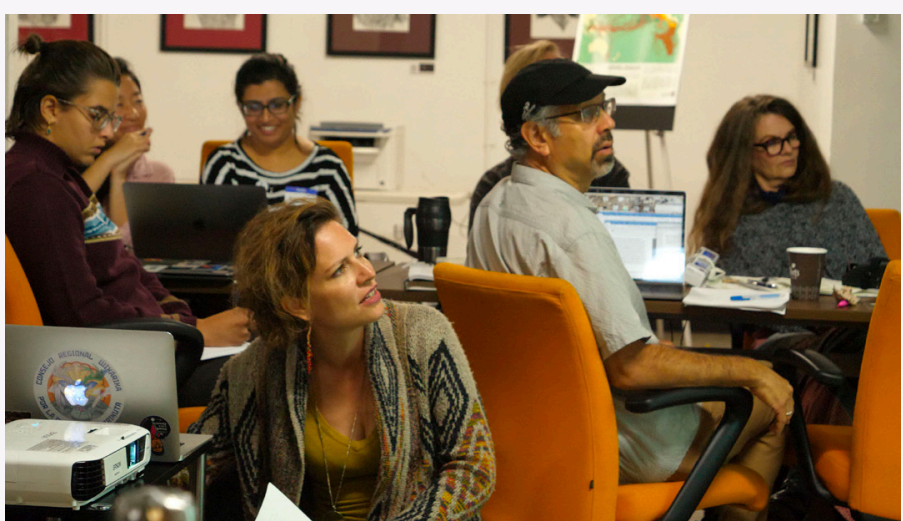

Diana Negrín and guerrillas.

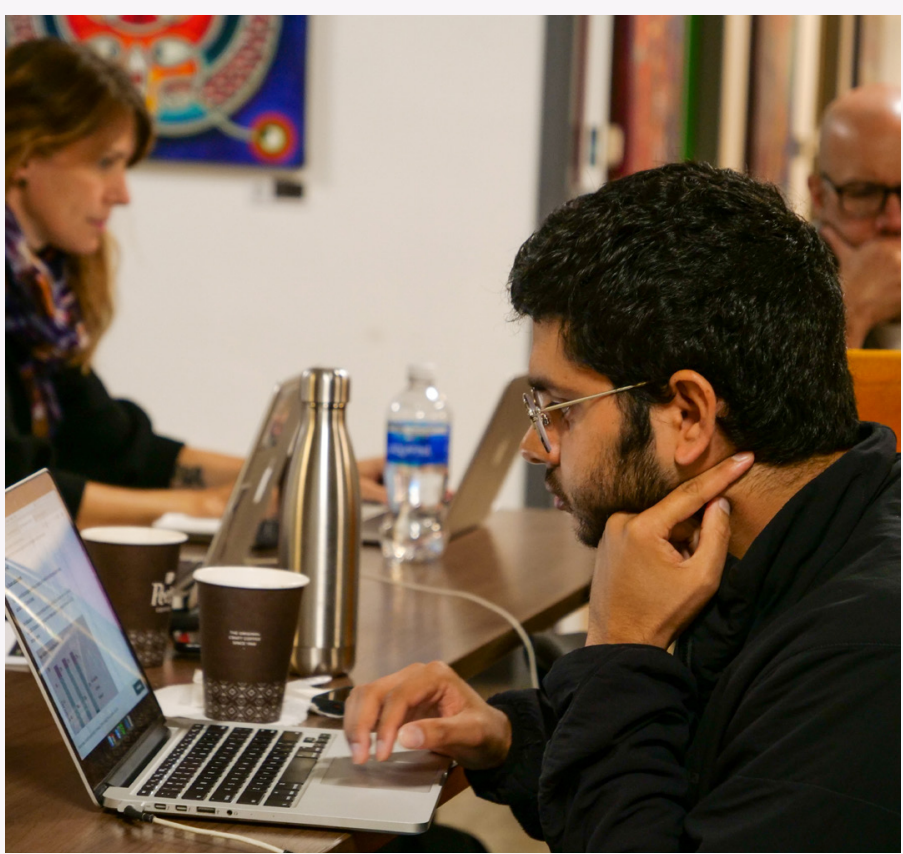

Jay Mahabal.

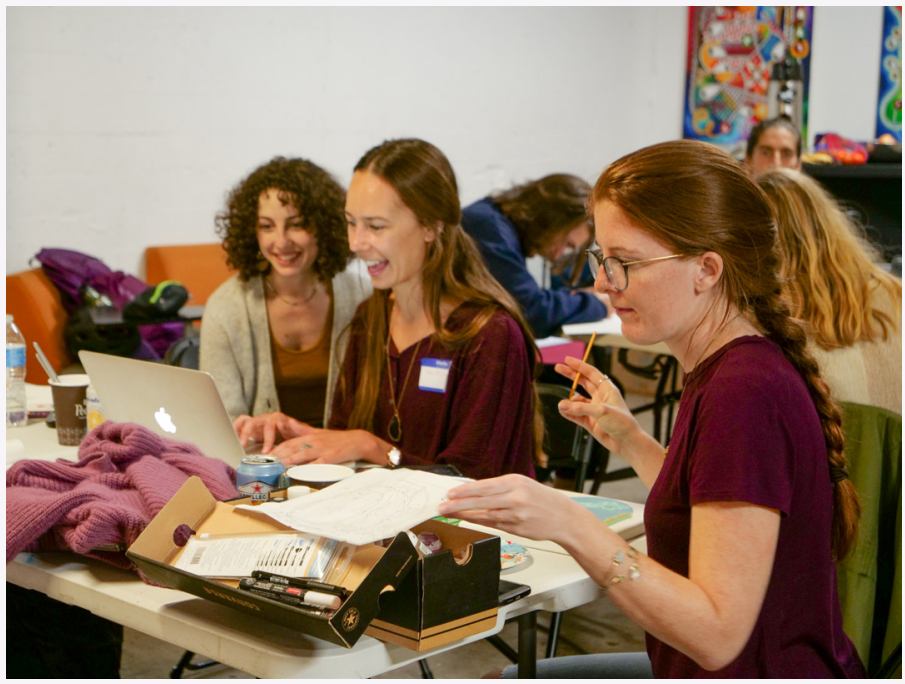

GC board vice president Maia Wachtel, Åse Mitchell, Whitney Newcomb. 


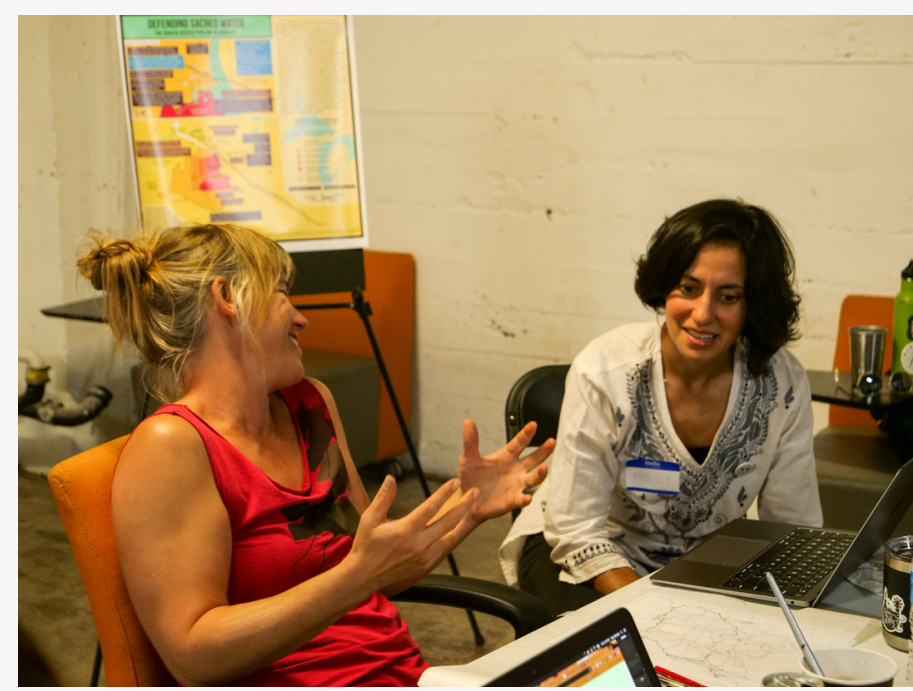

J. H. Blakeslee and Molly Roy.

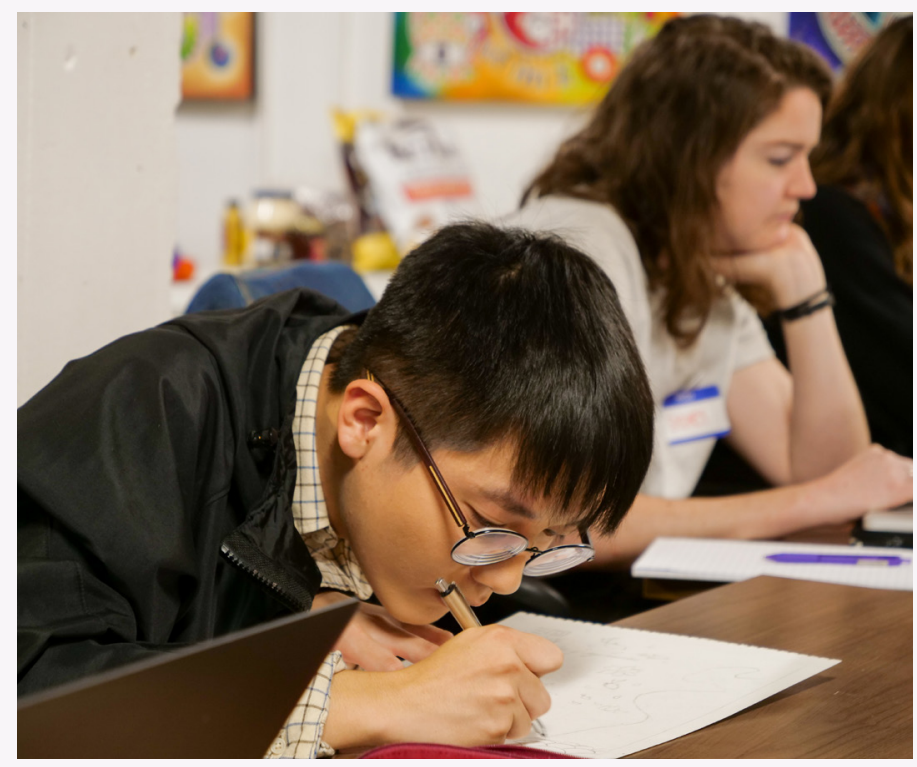

Max Shen and GC board secretary Sydney Johnson.

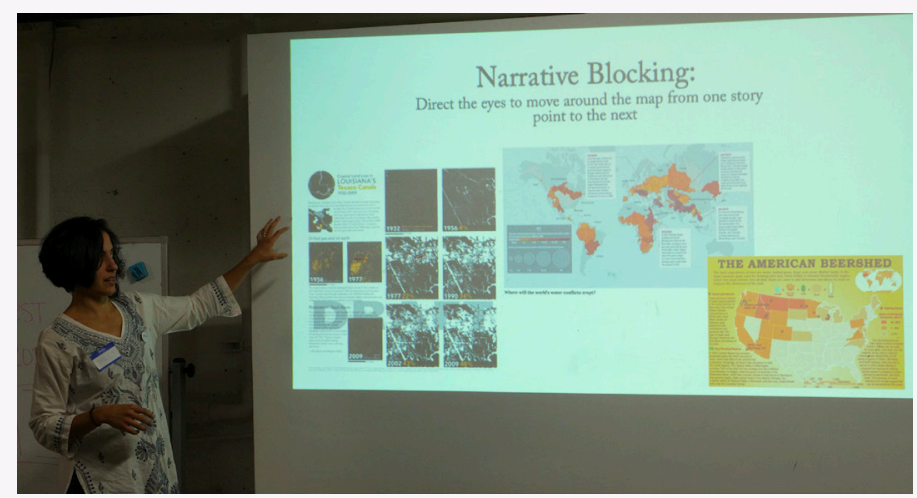

Molly Roy. become a tool that tracks, disciplines and distorts the represented ecosystems and peoples. In this talk, we will contemplate what forms of visual enunciation have the capacity to paint a more just portrait, considering specifically the ability to portray whole narratives and dignity in the practice of writing and visualizing an increasingly bordered world.

The guerrillas continued collaborating and sharing ideas throughout the morning and early afternoon. Guerrilla friend and Atlas in a Day co-organizer and contributor, J.H. Blakeslee, set up a sandwich bar where everyone found something delicious to eat. After lunch, with full bellies and a lot of good information and positive energy, the guerrillas settled back into their individual and team mapping projects.

At midafternoon, Guerrilla Cartography co-founder, former board member, and freelance cartographer, Molly Roy spoke on map design. Titled "Not just a pretty map: How to be an effective visual storyteller," her talk focused on how to effectively communicate concepts and data on a map, from color theory to data representation to narrative blocking. With all the talks concluded by early afternoon, and a 7:30 pm submission deadline looming, work on mapping continued.

Creating on computers, paper, and boards; using crayons, watercolors, embroidery thread, and other media, the challenge collaborators submitted 43 maps on the theme of migration by the 7:30 pm deadline. A single electronic file was compiled and one rough print on a scrappy printer was attempted by $9 \mathrm{pm}$, fulfilling the challenge.

\section{THE MAPPERS}

Whitney Newcomb's full-time day job is making maps at a computer. Atlas in a Day gave her an opportunity to explore other, non-digital mapmaking options. She said, "I had a canvas and some acrylics in my closet that were just screaming, 'Make me into a map!'” She waited patiently for the theme announcement at 9 pm on Friday night, and then turned to searching the internet to find her eventual subject: the longest migration in the world, that of the Arctic Tern. She spent the rest of the night and into the morning researching and drafting a map on 
paper, then transposing it to the canvas before heading to Oakland to meet up with a friend and go to the event.

I spent the day trying to get as little paint on the table and myself as possible while listening to the presenters and the other cartographers around me making incredible maps in all kinds of ways! We all shared paint and stories as this talented and passionate group of people came together to create something more than a map, more than a book-a community of cartography!

While Whitney created her map on her own (but in the company of that "community of cartography"), others worked in teams. Alex Epstein, Joshua Douglas Hubbard,

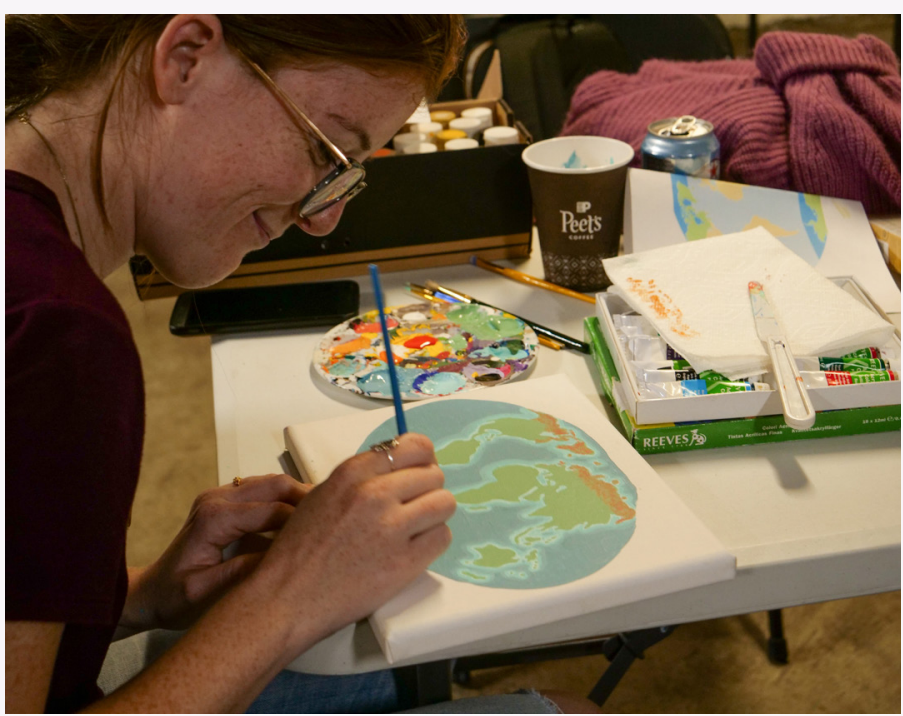

Whitney Newcomb.

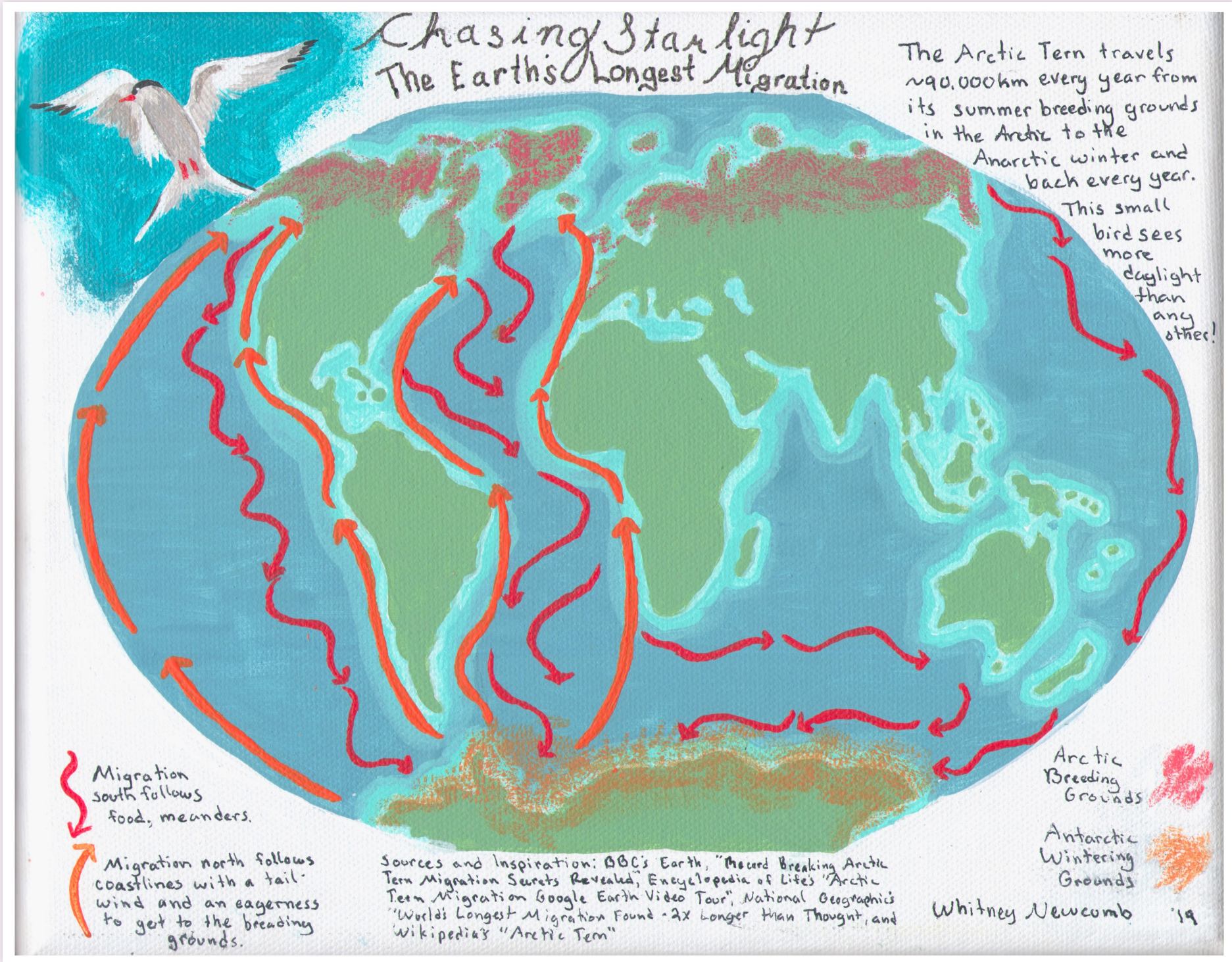

Chasing Starlight: The Earth's Longest Migration. 


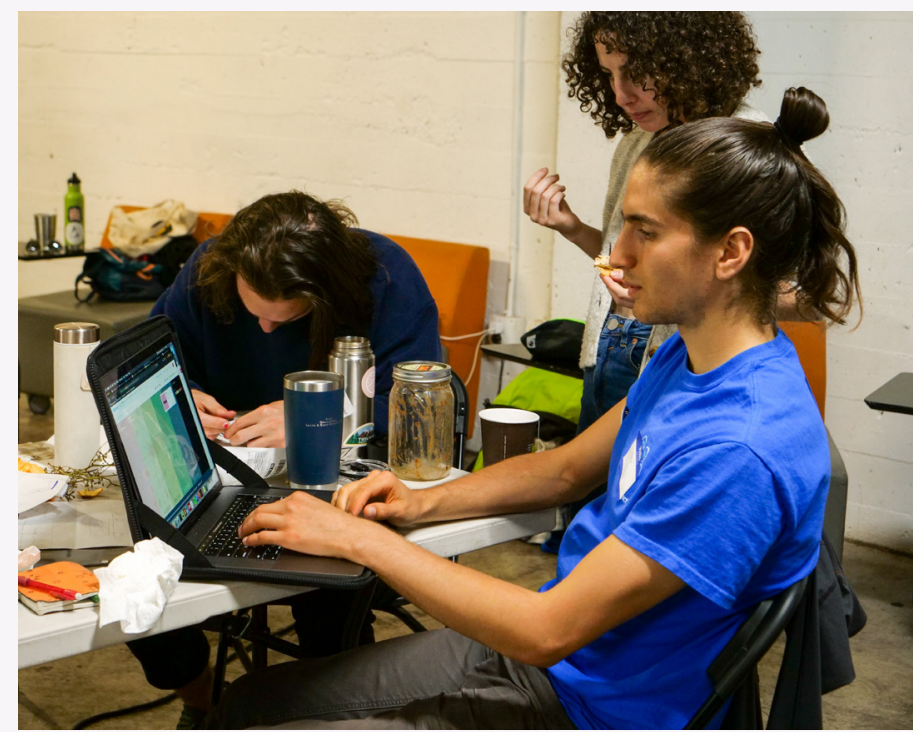

Joshua Douglas Hubbard, Maia Wachtel, and Alex Epstein.
Allison Whitaker, and GC board vice president Maia Wachtel joined their individual expertise to research, draft, and embroider a map.

Alex Epstein had never done any kind of cartography before, but as a graduate student researcher he frequently thinks about how to condense complex information into one meaningful figure. The Atlas in a Day challenge provided him "a new framework to approach that concept, and that was very exciting to me." Epstein studies new materials for recyclable plastics, and believes part of the solution to solving the problem of plastics is reducing our dependence on non-renewable resources like petroleum. He proposed to his team that they trace the "migration" of a petroleum molecule as it is processed into a plastic bottle. Epstein's team chose to embroider their map on card

\section{Ethylene Migration: From Crude Oil to Your Plastic Bottle}

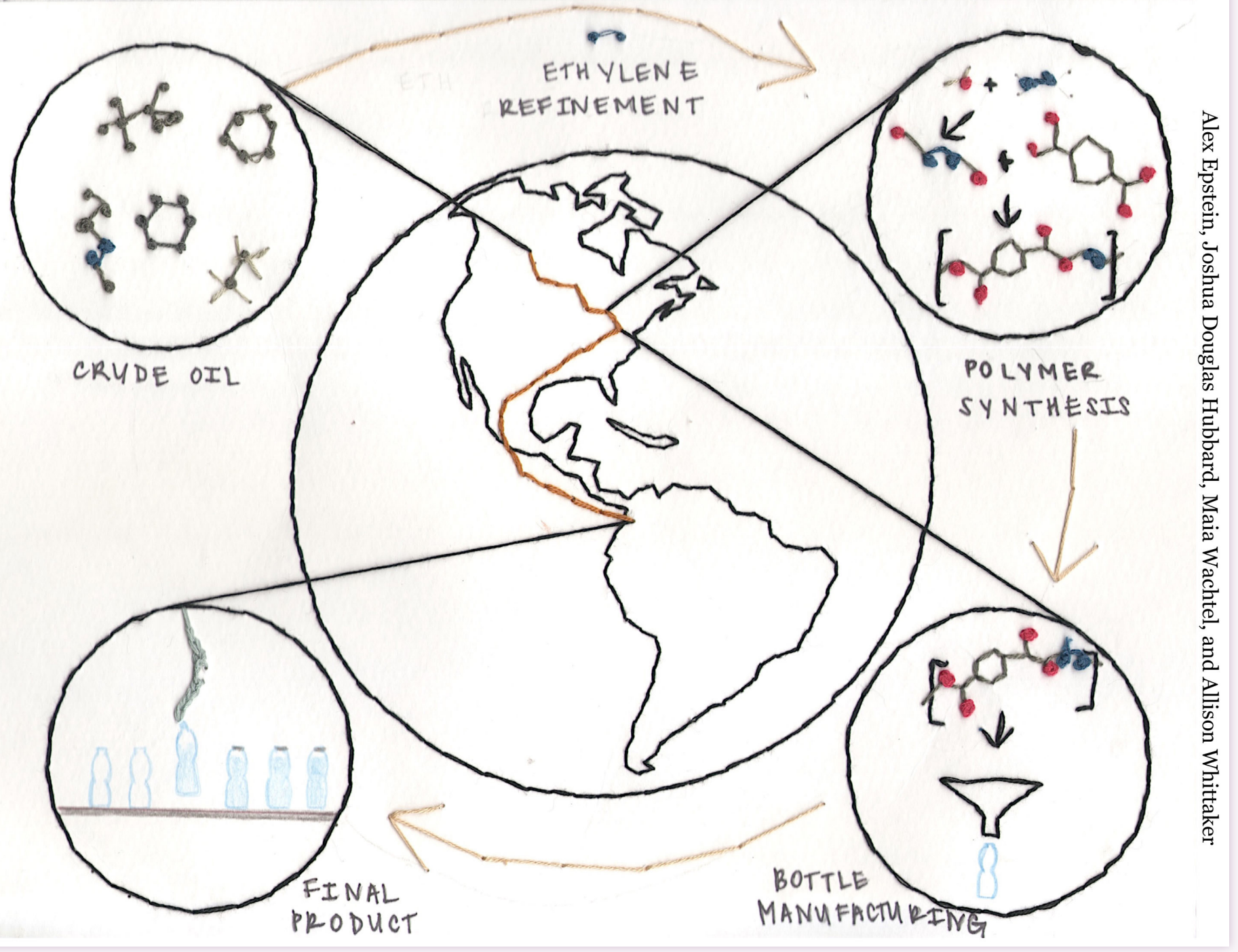

Ethylene Migration: From Crude Oil to Your Plastic Bottle. 
stock. After researching and sketching their design, they spent the bulk of their time embroidering the map.

Also working in a team, Sarah Dorrance and David Kardatzke brought their collective talents to the Oakland event to get started on their map and to hear the speakers, and then went back to San Francisco to finish and submit it. Dorrance, a mosaic artist, previously contributed to Guerrilla Cartography's Water: An Atlas and contributed to the GC blog with reflections on her map and experience. She also mounted the first public exhibition of the nascent Guerrilla Cartography group in 2012 when she included Mission Possible: A Neighborhood Atlas, in her art map show, "Maps Only: Radical Cartography in Contemporary Art," at Back to the Picture in San Francisco.
For their map, When a Road is a Wall, Dorrance and Kardatzke focused on the California migration of the California Newt (Taricha torosa), a creature whose migration they've witnessed multiple times near Livermore, California. Dorrance said, "GC offered us a place to highlight their migration plight and connect it by title to the wall being built on the US southern border to keep migrants out; and possibly 'to keep US citizens in.”'

Another 28 people joined the challenge remotely, many watching all the presentations via a live feed, from 14 other locations in the United States and five locations in Canada, Panama, and New Zealand.

From his studio in Missoula, Montana, Steven R Holloway contributed The Gate at the Crossing at El Coyote on the

\section{When a road is a wall}

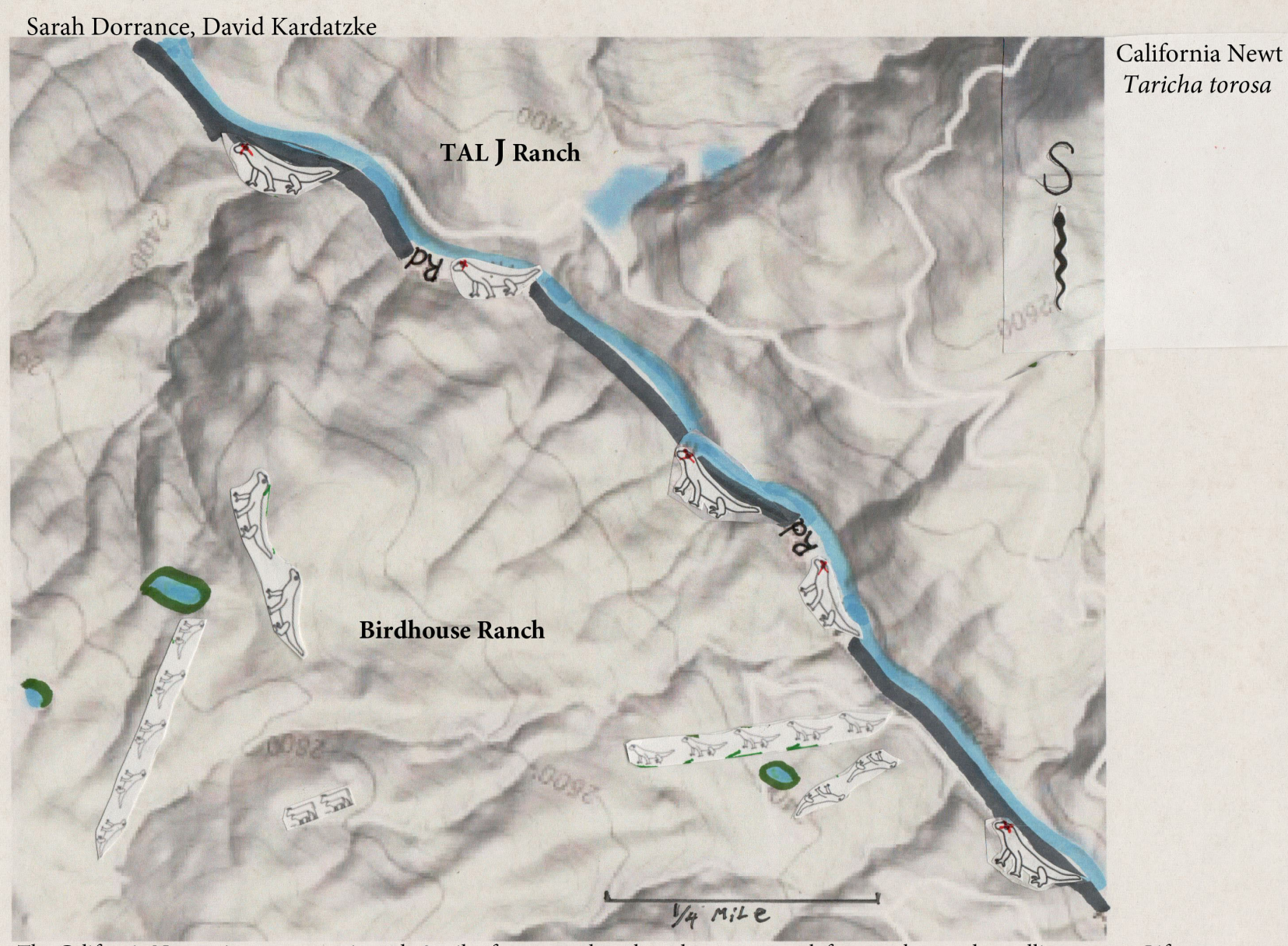

The California Newt migrates approximately 2 miles from vernal pools and streams to oak forests, chaparral or rolling grasses. Life expectancy is 20 years unless killed by traffic, or as eggs and larva they are eaten by non-native bull frogs, mosquito fish, and cray fish. They are naturally food for garter snakes passing on the protection of their skins toxicity. Californiaherps.com 2019 
Vamori Wash to Many Dogs Place, an evocative ink-oncrumpled-kōzo map marking a space of crossing between the United States and Mexico-a crossing Holloway has hiked. Reflecting on his journey there, he wrote, “... one day the green border people stop us. Ask to see ID. Demand to search our packs. Stopped. My heart is beating hard. Beneath my feet there is a stream of water. Moving across the border; the Vamori Wash. Cottonwoods. Open the gate. Close the gate. Does it really matter?..."

Hollloway, an artist mapmaker, used a string coated with brown-black ink to snap a line along the US/Mexico border. He blocked out the border gate, and then added it in via letterpress in orange-red. His source materials were many, including a USGS quad map showing where the Vamori Wash crosses the border in the Tohono O'odham Nation, southwest of Tucson, Arizona. The Tohono O'odham Nation is bifurcated by the border, and now reserved to a small part of their original land north of the border. "On all the maps I research there is always this line. This abstract line ... longitude this, latitude that. Sometimes on the maps there is nothing at all on the other side of the line." The ethereal nature of Holloway's geographic representations has inspired Guerrilla Cartography to open its last two atlases with his work.

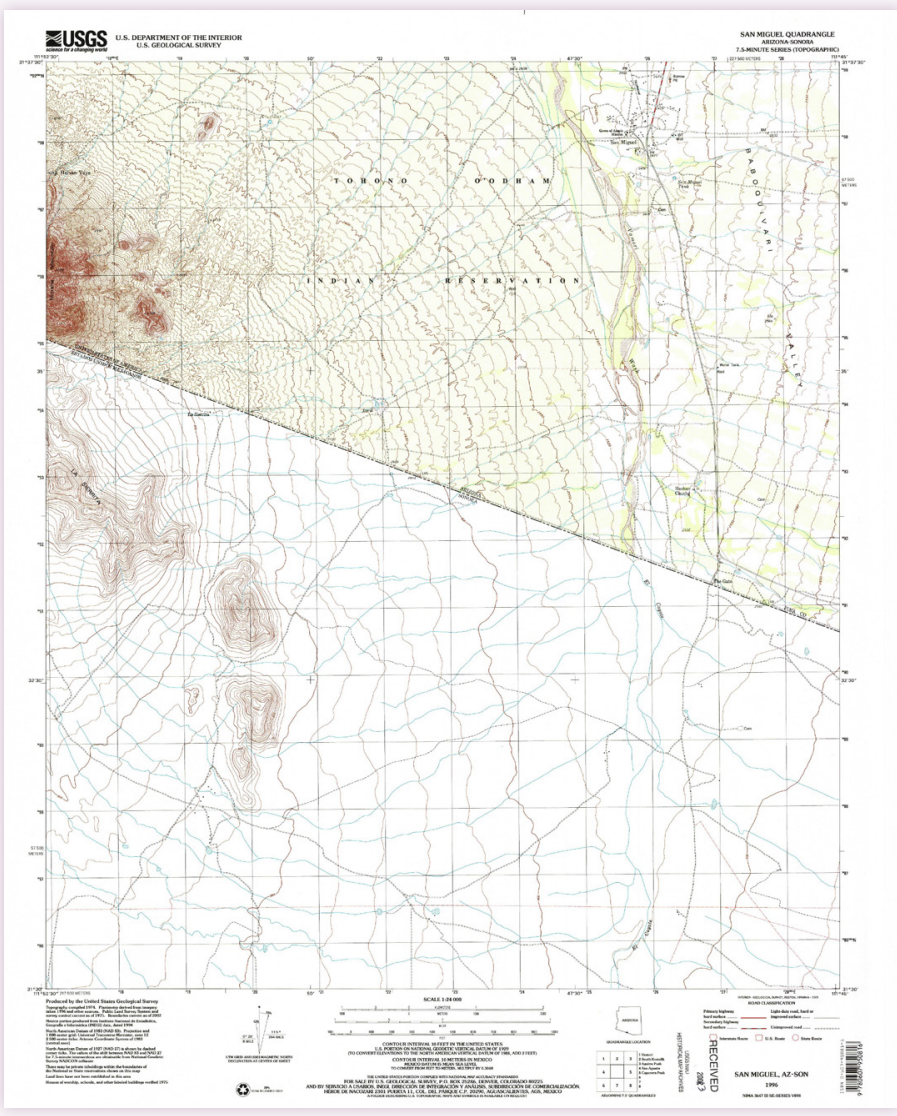

A USGS topographic map used as a source by Steven.

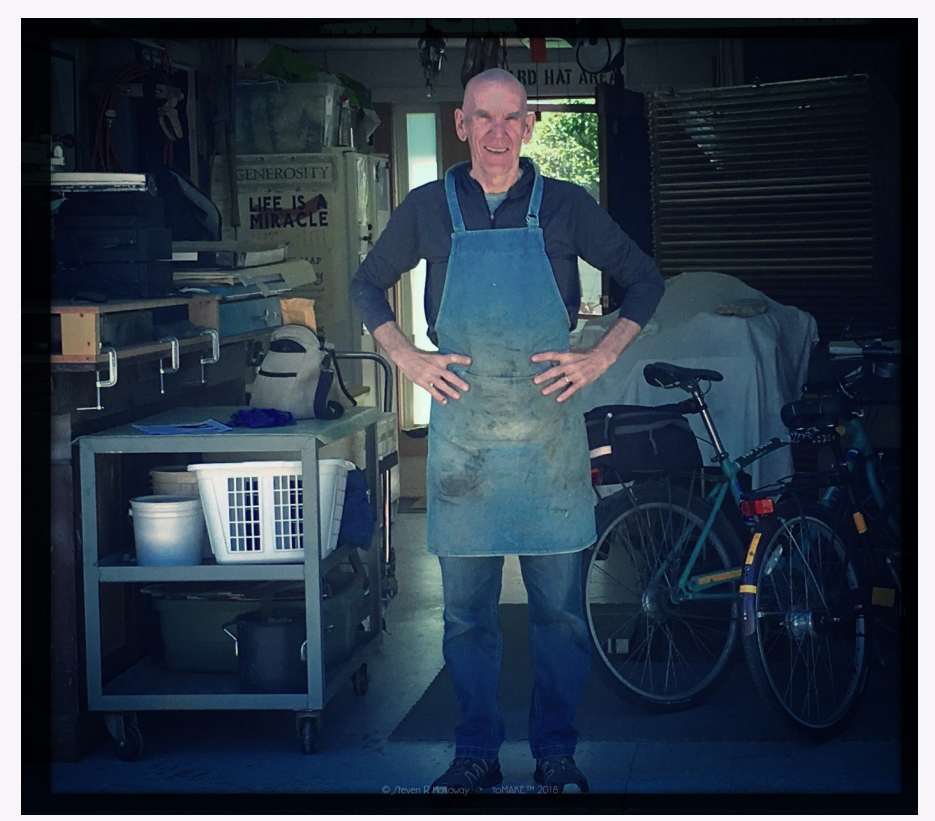

Steven R Holloway.

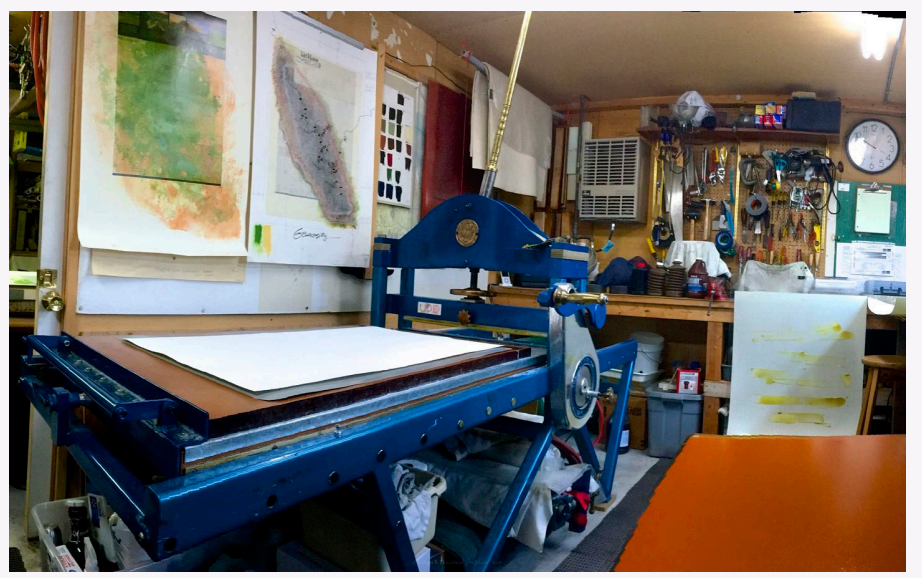

Steven R Holloway's studio.

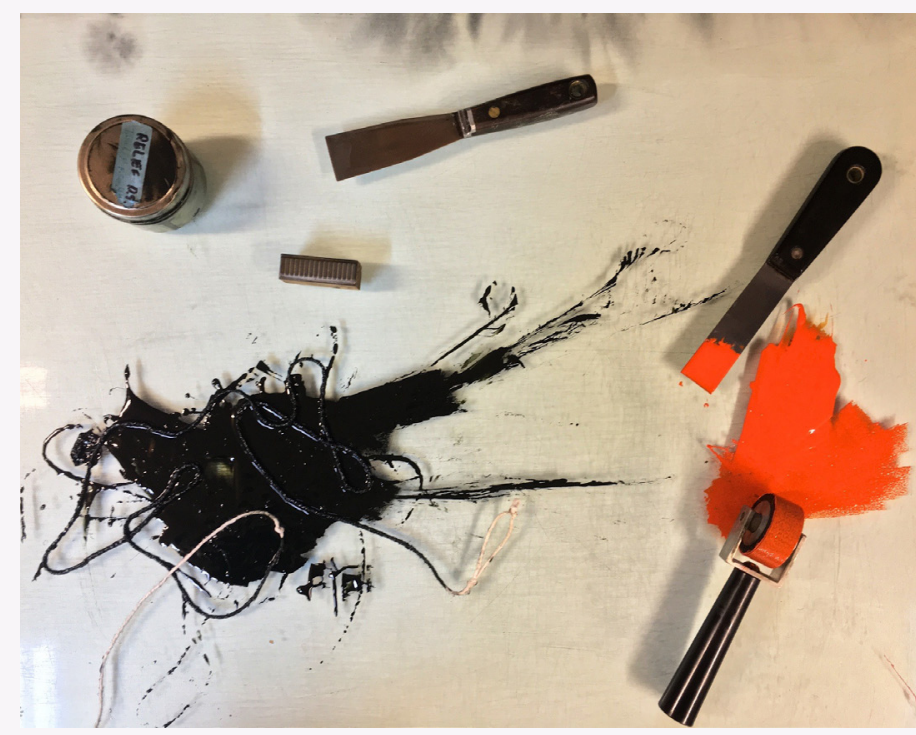

Some of Steven's materials. 


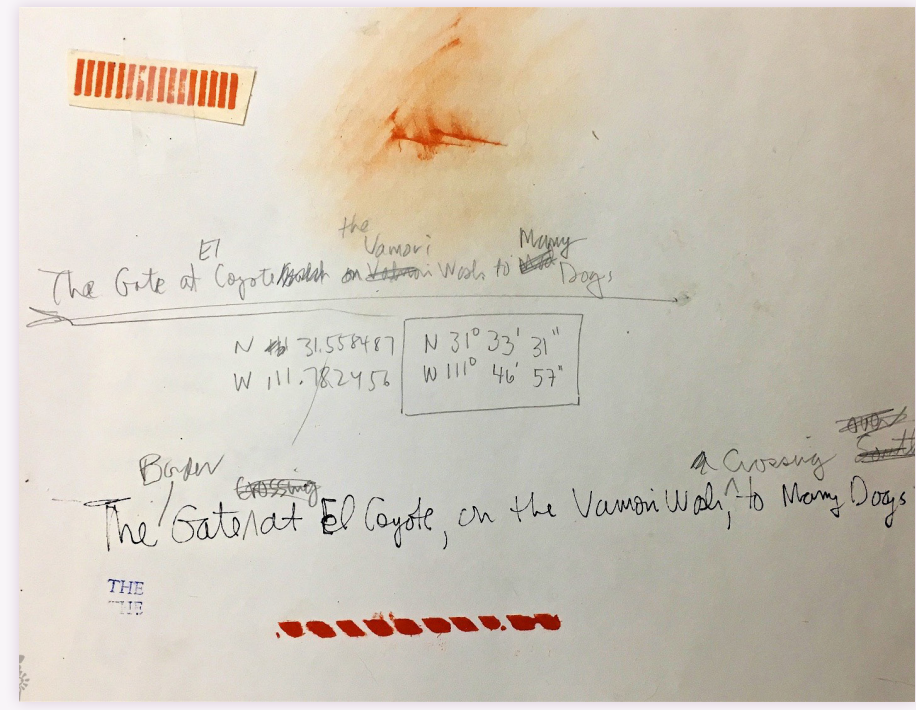

Steven's notes.

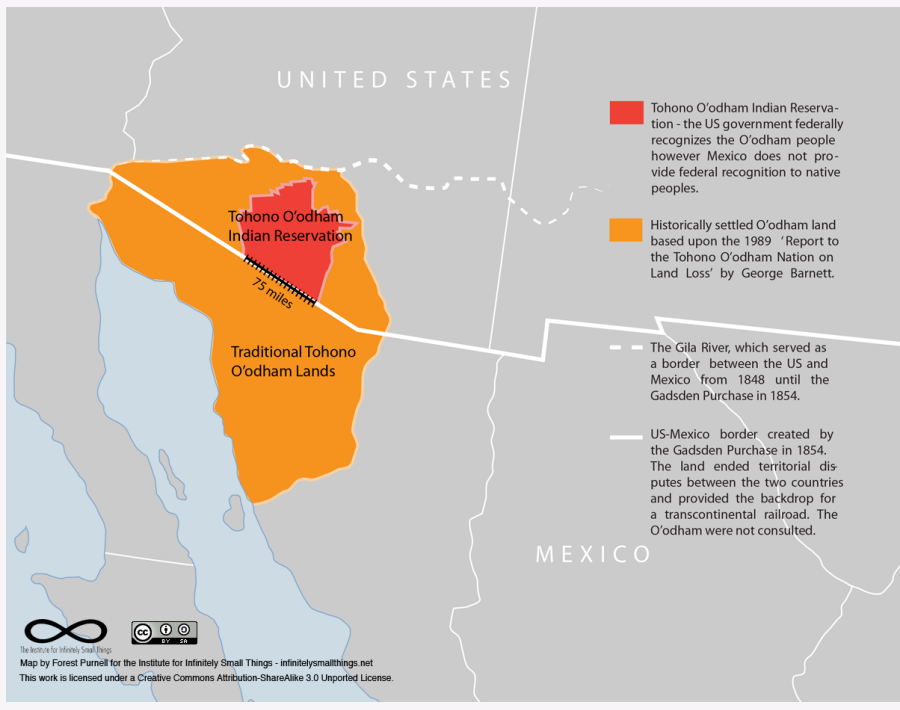

Tohono O'odham Nation. Map by Forest Purnell, CC-BY-SA 3.0.

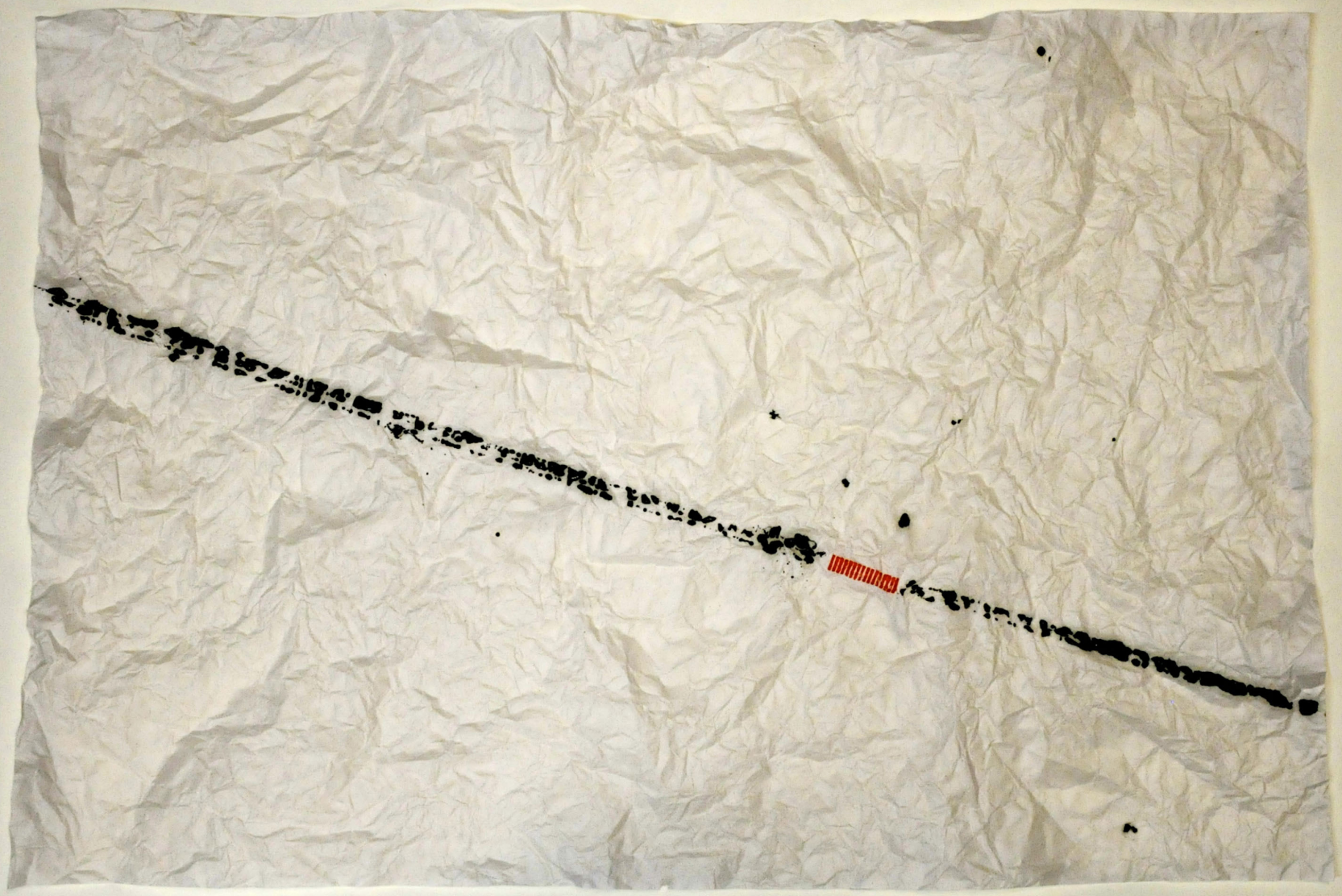

Ateven R Holloway toMake TM Press Missoula, Montana "The Gate at The Crossing at El Coyote on the Vamori Wash to Many Dogs Place" Tohono O'odham Nation

The Gate at the Crossing at El Coyote on the Vamori Wash to Many Dogs Place. 
Joseph Poirier and Brendan Rahman spent the Saturday of the Atlas in a Day challenge in Seattle working together-collaborating as a guerrilla cell-to create the map Migration Away From Flooded Land in Seattle, which shows where people and jobs could be displaced by sea level rise over the next 130 years. Colleagues at a transportation planning firm, they spent a large part of their day, "batt(ing) around a number of ideas but struggled to come up with something that we were interested in mapping, was meaningful, could be completed in one day, and was somewhat challenging." With a subject finally chosen and ample, familiar basemap data, they searched out the sea level rise data and, "interrogat(ed) the structure of the data and figure(ed) out how to best represent it."
Poirier and Rahman split up the mapping tasks "to play to our strengths." Poirier created the basemap and did the analytical work while Rahman created the design, happy, as Poirier said, "to do some recreational cartography ... It ended up being a great way to spend a Saturday." They were pleased with their final output and appreciated the opportunity to make a one-off map, as opposed to one that needed to adhere to design guidelines so that it could be incorporated into a suite of maps: "[The Atlas in a Day Challenge] allowed us to be more creative with the aesthetics than we often can be for work projects. We're looking forward to next year's Atlas in a Day!" Guerrilla Cartography doesn't plan to make them wait that long for another Atlas in a Day challenge.

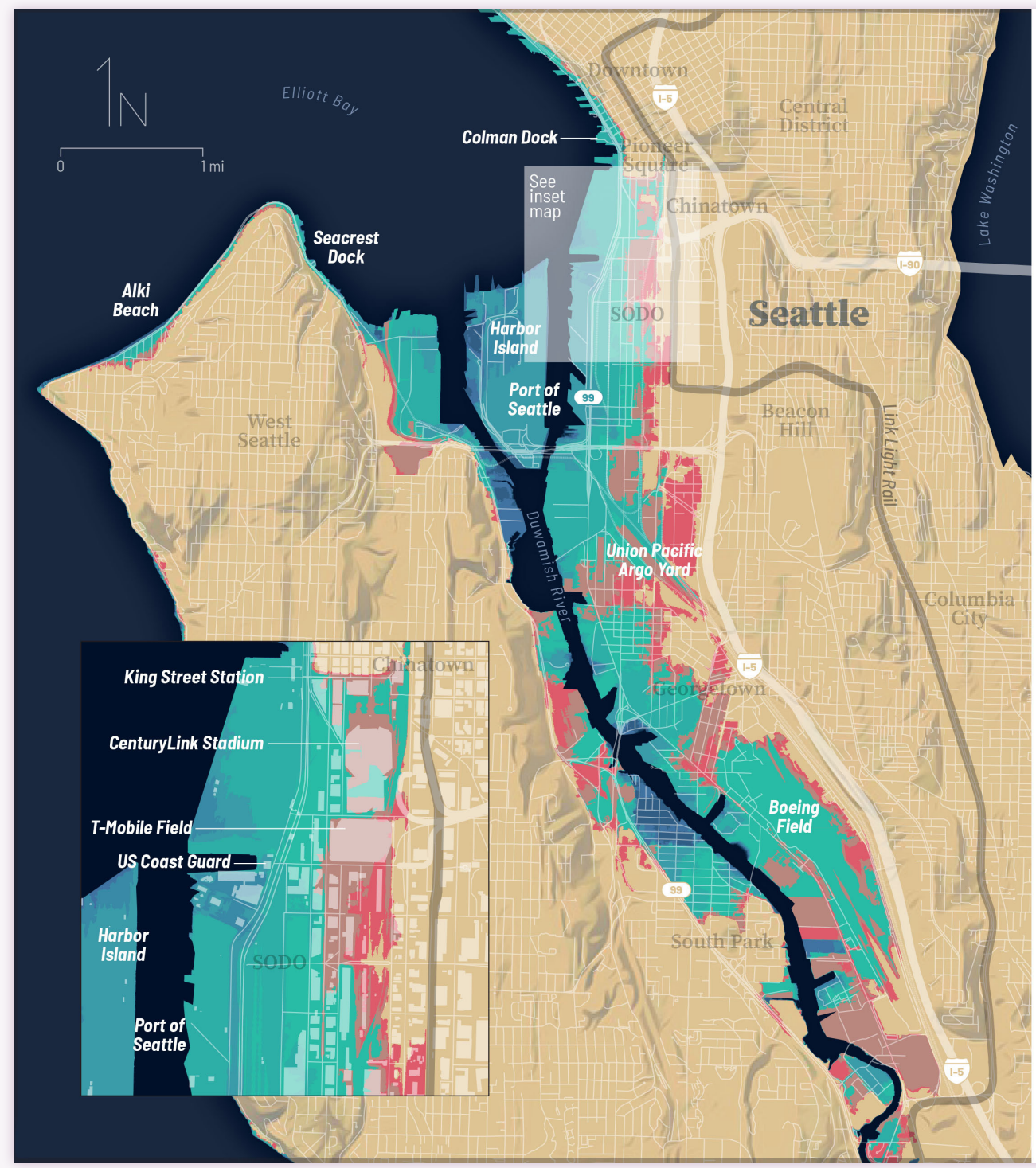

\section{Migration away from flooded land in Seattle}

How many people and jobs would be displaced by rising sea levels in the Duwamish River Valley?

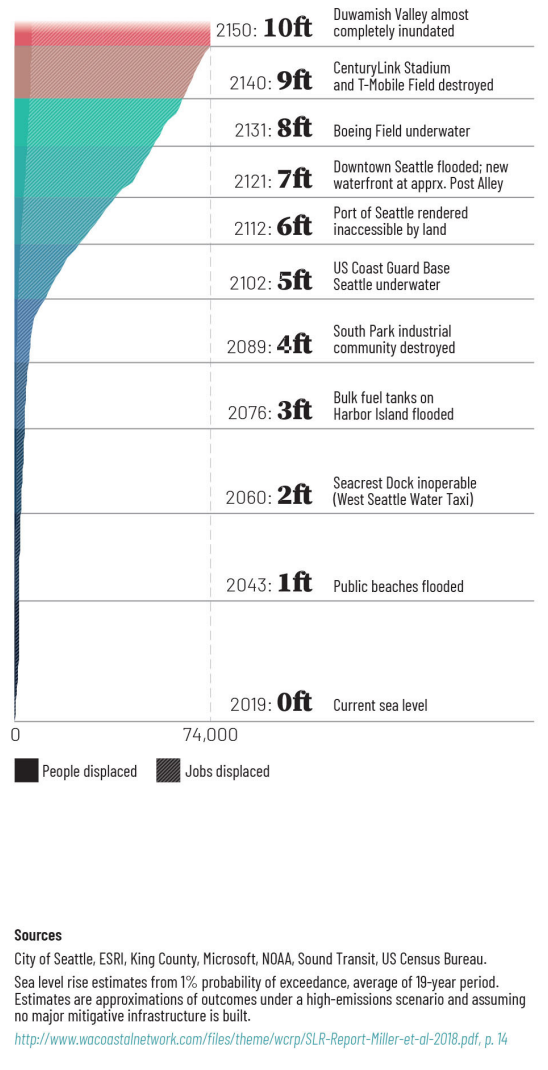

Migration Away From Flooded Land in Seattle. 
From Panama City, Panama, Mir Rodriguez Lombardo joined the challenge and, working from some previous research, chose to map Plant Migrations. He read peer-reviewed articles to decide which plants to map and employed QGIS and Inkscape to create his art, with "frantic iterations near the end." Unfortunately, a communication breakdown with GC staff (namely, me) resulted in only two of the four plant migration maps Lombardo made being published in the printed version. We regret this error and are pleased to publish his intended two-page spread here. A correction to the digital version is in the works and Lombardo's complete maps will appear there.

Of the event, Lombardo said it was "great to listen in on the talks and to feel part of a bigger thing." Guerrilla Cartography is pleased to have created a community of cartography and found that collaborations across the globe in real-time are not just possible, but fruitful.
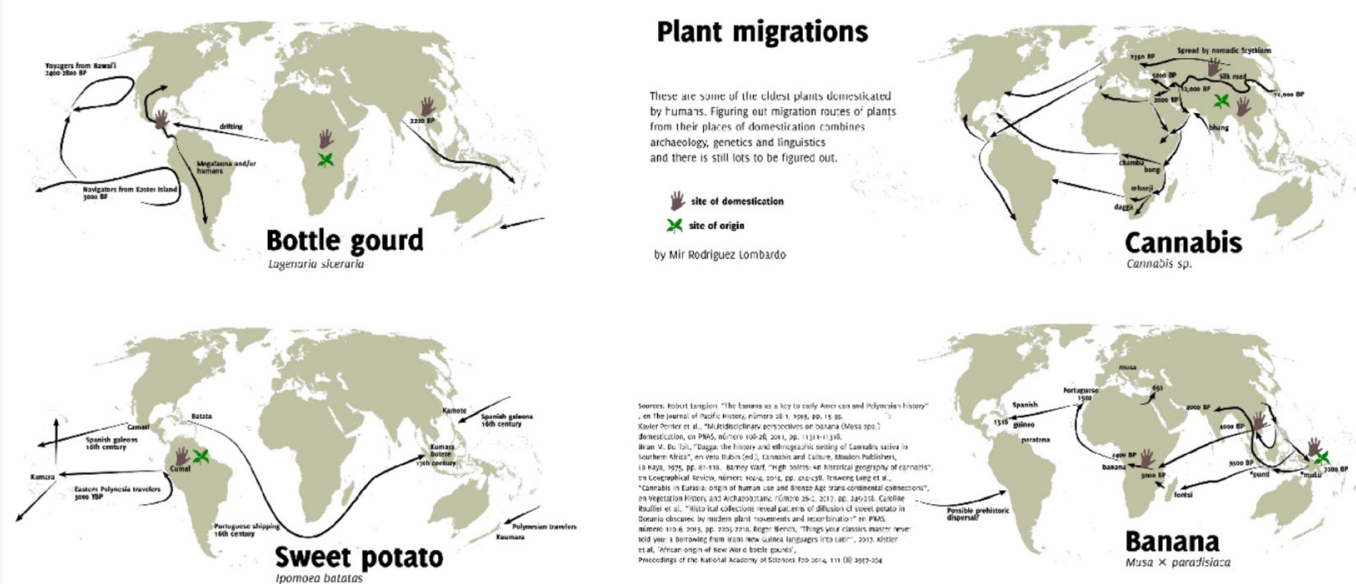

Plant Migrations

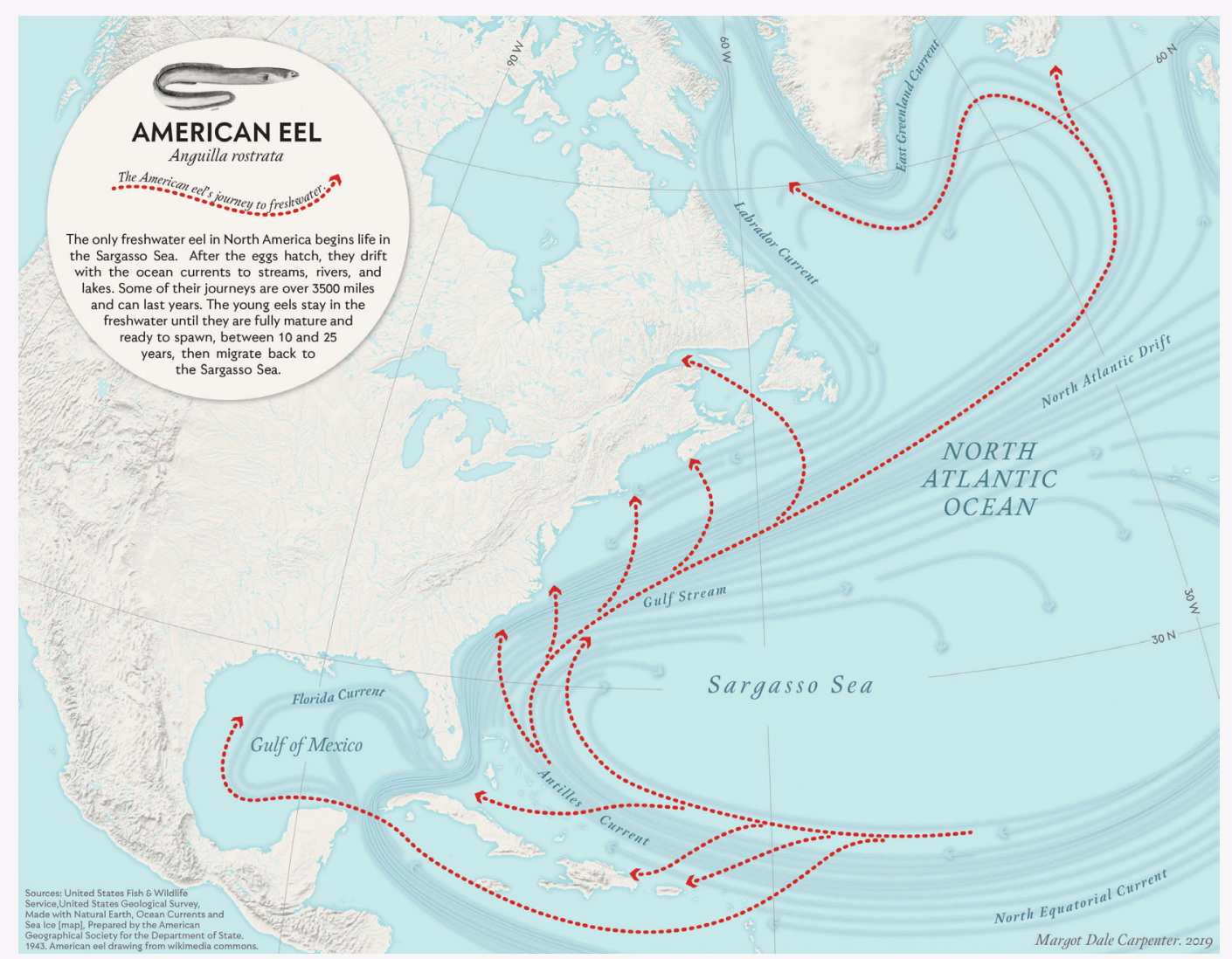

American Eel: The American Eel's Journey to Freshwater.
Margot Dale Carpenter, a freelance cartographer in Belfast, Maine, joined the challenge because, "I really like the idea of an artistic splurge effort and it seemed like a great way to push my abilities (and) limits. Instead of over-thinking a project, this demanded a run and dive -in. I liked that." Her map, American Eel: The American Eel's Journey to Freshwater is based on a well-established migratory pattern that passes by her town; she has seen the American Eel in the Atlantic Ocean off the dock in downtown Belfast. While she loves hand-drawing maps, she decided on a digital medium because it's easier to deliver a higher quality image (no scanning required) and the challenge time limit made it more efficient to work digitally. 
After the Challenge Day, GC took a little time to reflect on the maps that were created and then ordered them into a sort of narrative, both graphic and philosophical, by choosing just one of the myriad possible arrangements. A final document was published online within a week of the challenge; click here to download.

The maps in this atlas interpret the theme of migration in diverse ways, considering the movements of people, animals, climates, physical materials, and cultural artifacts over time and space. Some of them represent the culmination of years of research on a critical topic; others are quick sketches inspired by current events and concerns. Collectively, they add substance and content to one of the most critical issues our planet faces today.

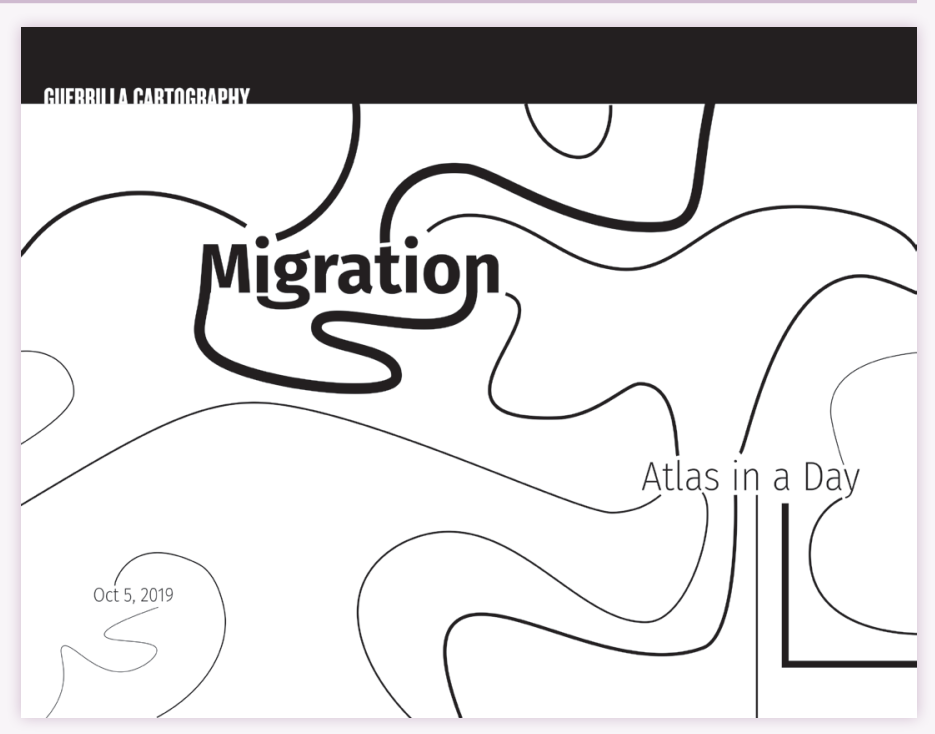

The atlas cover.

\section{ABOUT GUERRILLA CARTOGRAPHY}

The brainchild of Darin Jensen, Guerrilla Cartography (GC) has its antecedents in the Geography Department at UC Berkeley. Then the staff cartographer and cartography instructor at Berkeley, Jensen organized interested students to create Mission Possible, an atlas of the Mission District of San Francisco, in 2011. Considering the class as the crowd, it was Jensen's first foray into crowdsourcing cartographic content for a thematic atlas.

GC was founded in 2012 on the idea that a new paradigm for cooperative and collaborative knowledge-caching and -sharing could have a transformative effect on the awareness and dissemination of spatial information. With the able assistance of Molly Roy and other UC
Berkeley scholars and cartography students, the initiative sought to globally crowdsource maps on a theme, compile them into an atlas, and produce a printed volume in under a year. With contributions from over 120 collaborators in thirteen countries, Food: An Atlas, was published and printed seven months after the initial call for maps. GC became a 501(c)(3) registered nonprofit corporation in 2014 and published its second atlas, Water: An Atlas, in 2017. In February 2020, GC announced the theme for their next atlas, "Shelter"; see their call for maps. To read more about our efforts, check out "Guerrilla Cartography: Promoting Diverse Perspectives and the Expansion of the Cartographic Arts,” by Alicia Cowart and Susan Powell, in Cartographic Perspectives 92. 